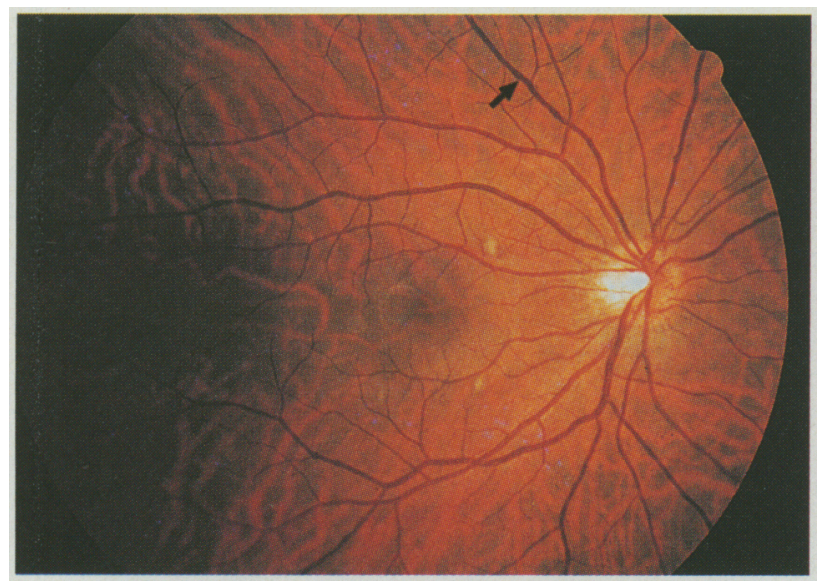

Figure 3. Right eye 2 months later. Most cotton wool spots have resolved. Tiny yellow precipitates at the macula are artifacts. Irregularity of caliber of the retinal veins is persistent (arrow).

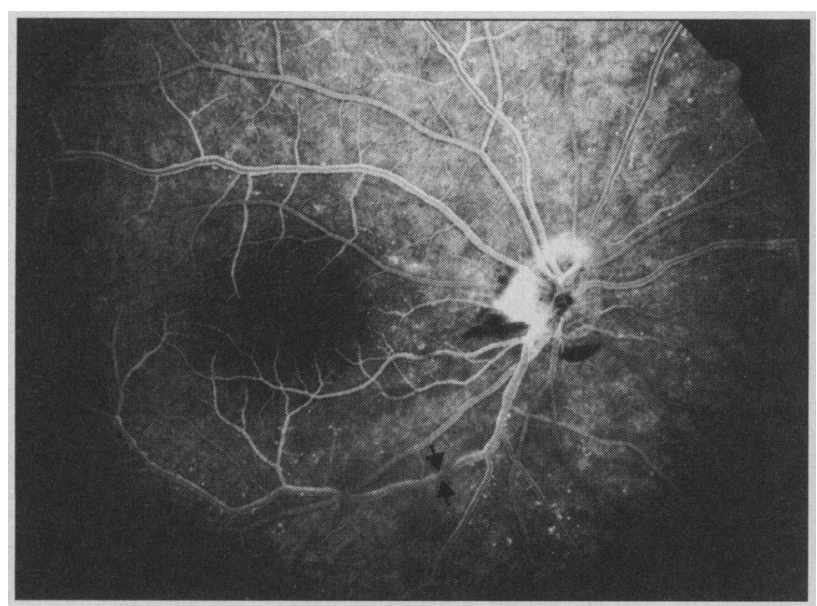

Figure 4. Fluorescein angiography at second manifestation of vitreous floaters in the right eye. Note parapapillary preretinal hemorrhages, a small neovascularizationlike structure, multiple microaneurysms, staining of the walls of the retinal veins (arrows) and mild masking caused by the inferior vitreous hemorrhage.

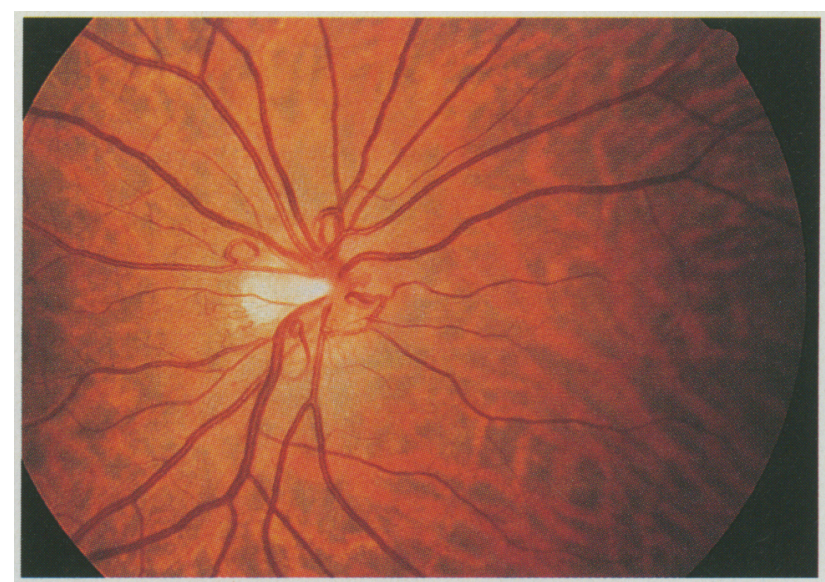

Figure 5. Six months later. Note new vascular loops on the right optic disc.

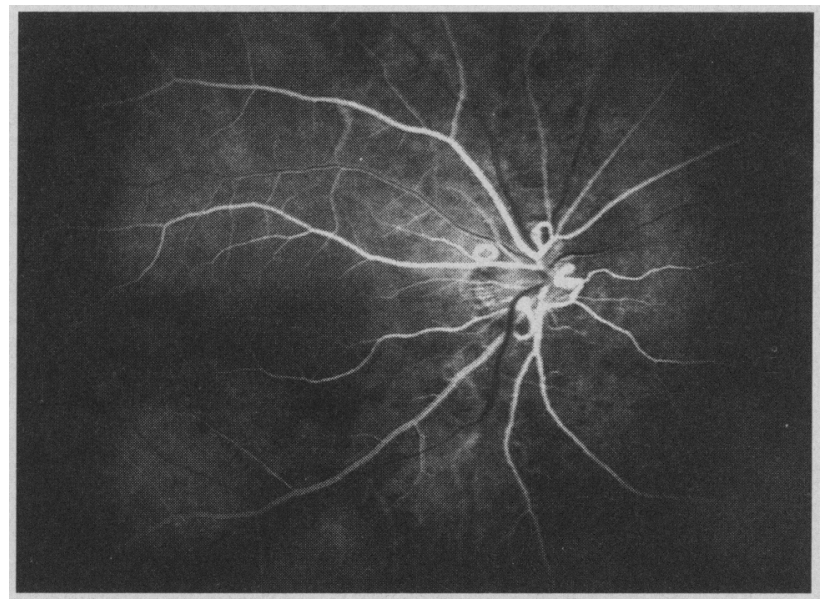

Figure 6. Fluorescein angiogram obtained at the same time as Figure 5. The vascular loops fill in the early arterial phase with the arterial retinal vasculature. The patchy areas are artifacts due to aging of the fluorescein angiogram (10 years old). cilliary collaterals that characterize vein occlusions, which fill during the venous filling phase. The pathological mechanism for the development of arterial vascular loops in this patient is unknown. In the case presented here, no ocular complications occurred after the development of these loops in both eyes and no underlying systemic illness became evident during the next 10 years of observation.

Tamara Wygnanski-Jaffe, $M D$ Howard Desatnik, MD

Giora Treister, MD

Joseph Moisseiev, MD

Tel Aviv, Israel

Reprints: Joseph Moisseiev, The Goldschleger Eye Institute, The Sheba Medical Center, Tel Hashomer 52621 , Israel.
1. Degenhart W, Brown GC, Augsburger JJ, Magargal L. Prepapillary vascular loops. Ophthat mology. 1981:88:1126-1131

2. Shakin EP, Shjelds JA, Augshurger JJ, Brown GC. Clinicopathologic correlation of a prepapillary vascular loop. Retina. 1988;8:55-58.

\section{Esthesioneuroblastoma Presenting With Epiphora in a Young Child}

Esthesioneuroblastoma (ENB) is an uncommon tumor believed to arise from the olfactory epithelium.' This neoplasm has rarely been reported in children, with only 12 cases reported to date among patients younger than 10 years. ${ }^{2}$ The usual initial symptom in children, as in older patients, is nasal obstruction or epistaxis ${ }^{3}$; consequently, the tu- mor is often first seen by an otorhinolaryngologist. We report a case of ENB in a young child in whom the initial symptom was epiphora; to our knowledge, this initial symptom is previously unreported, and ENB must now be considered in the differential diagnosis of epiphora in childhood.

Report of a Case. A white 6-yearold male child was seen on January 25,1996 , with a 5-month history of epiphora in the right eye. His condition was initially diagnosed elsewhere as conjunctivitis and was treated with topical antibiotics. His medical history was unremarkable.

Initial examination results revealed slight inflammation of the lacrimal punctum of the right eye, suggesting possible canaliculitis. A 


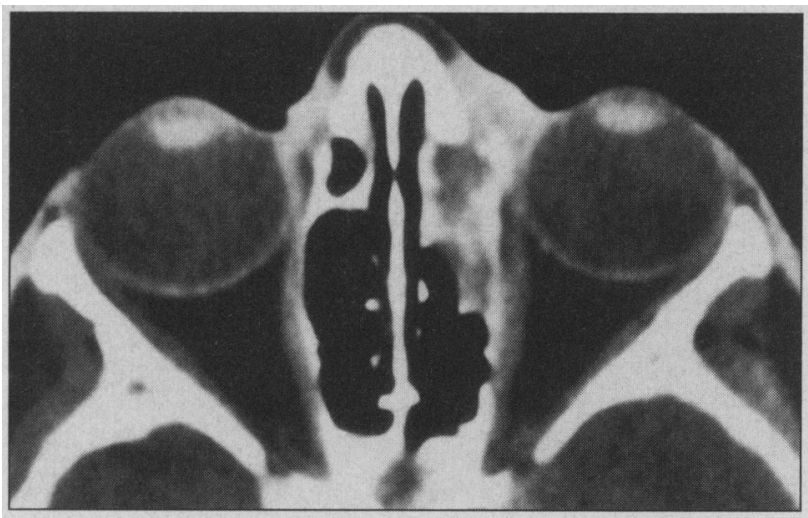

Figure 1. Axial view of contrast-enhanced computed tomographic scan of the brain demonstrates tumor involvement of the right ethmoid sinus and tacrimal sac fossa.

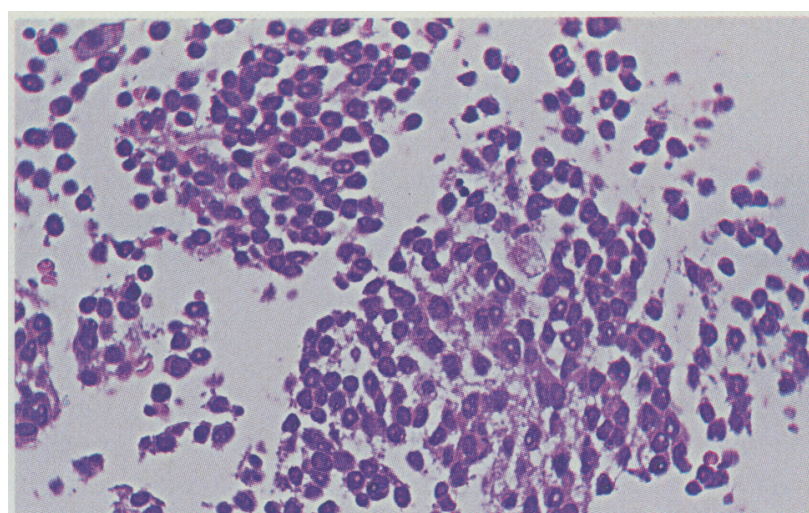

Figure 2. Light microscopy of tumor beneath nasal mucosa, demonstrating histological characteristics of esthesioneuroblastoma (hematoxylin-eosin, $\times 200$ ) conjunctival smear was obtained and empirical treatment with topical tetracyclines was started. After 15 days of treatment, the epiphora persisted and cultures were negative for organisms.

The lacrimal trajectory was examined with dacriocystography, which revealed a filiform passage of contrast with displacement of the lacrimal sac and deviation of the lacrimonasal duct as the result of a mass effect. After consulting with the otorhinolaryngologist, a fleshy rosecolored mass was detected in the right upper nasal fossa. A biopsy specimen was obtained for histopathological study. There were no enlarged cervical lymph nodes, and the rest of the examination results proved normal.

Computed tomography of the brain showed a large tumor at the right upper nasal fossa extending to the maxillary sinus and ethmoidal cells (Figure 1). Evaluation was completed with magnetic resonance imaging, which confirmed the extent of the tumor with no evidence of intracranial spread or intraorbital invasion outside of the lacrimal sac fossa.

The histopathological examination results identified respiratory mucosa and bone fragments infiltrated by a small cell tumor. The cells were highly basophilic and arranged in the form of cords or nests; the nucleus was hyperchromatic, with frequent mitoses and a scarce cytoplasm (Figure 2). This confirmed the diagnosis of ENB.

After completion of the histopathological study and analysis of tu- mor spread, a paralateronasal rhinotomy was performed extending to the upper lip, with complete extirpation of the tumor. The patient is presently receiving chemotherapy with cisplatinum, and is undergoing follow-up examinations. There has been no evidence of tumor recurrence for 9 months.

Comment. Approximately $74 \%$ of all patients with olfactory ENB have ophthalmologic disorders in the course of the disease. However, patients with olfactory ENB who initially experience eye problems tend to be seen at a later stage of the disease, perhaps because ophthalmologic symptoms such as epiphora are not worked up as aggressively as symptoms of epistaxis. Olfactory ENB should be included in the differential diagnosis of every patient with ocular and nasal symptoms. ${ }^{4}$

The histogenesis of these tumors remains uncertain, though the olfactory epithelium is the most widely accepted place of origin. ${ }^{3}$ The differential diagnosis must be established with other small cell tumors, such as transitional cell carcinomas, plasmocytomas, malignant lymphomas, sarcomas, and rhabdomyosarcomas. Management is also controversial, though most authors advocate surgery with radiotherapy, chemotherapy, or both. ${ }^{1.5}$ Owing to the rarity of this tumor, insufficient experience has been accumulated to suggest the factors that influence prognosis.

We believe that despite its rarity, this type of tumor should be taken into consideration when establishing the differential diagnosis of late epiphora in children.

Mercedes Hurtado-Sarrió, MD Juan R. Artacho-Tejederas, MD Fernando Riblón-Bornao, MD Cármen Guillén-Fernández, MD Alicante, Spain

Antonio M. Duch-Samper, MD Valencia, Spain

1. Djalilian M, Zujko RD, Weiland LH, Devine KD. Olfactory neuroblastoma. Surg Clin North Am. 1977;57:751-762.

2. Bobele GB, Sexauer CH, Barnes PA, Krous HF Esthesioneuroblastoma presenting as an orbital mass in a young child. Med Pediatr Oncol. 1994:22:269-273

3. Perkkio M, Majuri S, Hanninen A, Paljarvi L. A child with esthesioneuroblastoma with metastases to the spinal cord and bone narrow. Med Pediatr Oncol. 1991;19:66-69.

4. Rakes SM, Yeatts RP, Campbell RJ Ophthalmic manifestations of esthesioneuroblastoma. Ophthatmology. 1985;92:1749-1753.

5. Brunet J, Sola C, Mesia R, et al. Esthesioneuroblastoma: experience from 4 cases treated with radiotherapy and neoadjuvant chemotherapy. Acta Otorrinolaringol Esp. 1995;46:97-100

Reprints: Mercedes Hurtado-Sarrió, MD, Gran Via Fernando el Católico 22-7, Valencia 46008, Spain.

\section{Ocular Neuromyotonia 18 Years After Radiation Therapy}

Report of a Case. The patient is a 33-year-old woman. At age 6 years she underwent partial resection of a cerebellar ependymoma followed by radiation therapy to the spinal axis $(27 \mathrm{~Gy})$ and placement of a ventriculoperitoneal shunt. She had no visual symptoms until 18 years later, 